\title{
A randomised placebo controlled study to assess the effects of cholinergic treatment on muscarinic receptors in Alzheimer's disease
}

\author{
P M Kemp, C Holmes, S Hoffmann, S Wilkinson, M Zivanovic, J Thom, L Bolt, J Fleming, \\ D G Wilkinson
}

Objective: To determine the effects of cholinergic treatment on the muscarinic receptor in patients with Alzheimer's disease.

Methods: 12 patients with mild to moderate Alzheimer's disease and six controls were studied. The patients underwent ADAS-COG psychometric assessment and SPECT brain imaging with ${ }^{123}$ | quinuclidinyl benzilate (QNB), to demonstrate the postsynaptic muscarinic $M 1$ receptor, before being randomised in a double blind study to receive either an acetylcholinesterase inhibitor (donepezil) or placebo for four months. Following this, the ADAS-COG and the ${ }^{123}$-QNB receptor scan were repeated. The controls were imaged on one occasion only. All image analyses were undertaken using SPM99.

Results: ${ }^{123}$ I-QNB imaging showed a significant relation between baseline psychometric impairment and deficits on scanning. Both placebo and actively treated groups had reductions in ${ }^{123} \mathrm{I}-\mathrm{QNB}$ uptake. Greater reductions in receptor binding were demonstrated in the placebo group than in those receiving active treatment. Intraindividual reproducibility of the ${ }^{123}$ I-QNB imaging technique appeared highly robust.

Conclusions: The results suggest that ${ }^{123} \mathrm{I}-\mathrm{QNB}$ uptake is better preserved in Alzheimer's disease patients on cholinergic treatment than on placebo. Cholinergic treatment may play a neuroprotective role. Sequential ${ }^{123}$ I-QNB imaging seems to be a powerful tool in monitoring the response of these receptors to disease modifying treatments.

$\mathrm{T}$ he deposition of amyloid plaques and tangles within cerebral tissue in patients with Alzheimer's dementia is associated with disruption of the cholinergic nervous system, causing depletion of the neurotransmitter acetylcholine. ${ }^{1}$ The administration of acetylcholinesterase inhibitors (AChE-I) appears to provide benefit in approximately 40$50 \%$ of patients, albeit temporarily. ${ }^{2}$ There is also a suggestion from a clinical trial of a neuroprotective effect of AChE-I treatment. ${ }^{3}$

Iodine-123 quinuclidinyl benzilate (QNB) is a radioactive tracer that can be used to demonstrate in vivo the $\mathrm{Ml}$ receptor that is predominantly situated on the postsynaptic muscarinic receptor. ${ }^{4}$ This pilot study was designed to assess the effects of cholinergic treatment on these postsynaptic receptors using ${ }^{123} \mathrm{I}$-QNB in vivo imaging in a randomised, double blind, pilot study in patients with Alzheimer's disease.

\section{METHODS}

\section{Recruitment}

Twelve patients who fulfilled the NINCDS-ARDRA criteria ${ }^{5}$ for probable Alzheimer's dementia were recruited for this study at the memory clinic, Moorgreen Hospital, Southampton, by a consultant in old age psychiatry. Six healthy controls without a history of head injury or neuropsychiatric illness, and with no apparent cognitive impairment, were also recruited.

\section{Trial design}

The 12 patients with Alzheimer's disease underwent baseline ADAS-COG (Alzheimer's disease assessment scale-cognitive behaviour) psychometric assessment and ${ }^{123} \mathrm{I}$-QNB imaging followed by randomisation in a double blind trial to receive either four months of treatment with an AChE-I (donepezil $5 \mathrm{mg}$ daily increasing to $10 \mathrm{mg}$ at four weeks) or placebo. Following this period, and before discontinuation of the allocated treatment, the psychometric assessment and brain scan were repeated. The six controls were imaged on one occasion only and did not undergo formal psychometric testing.

\section{${ }^{123} \mathrm{I}-\mathrm{QNB}$ preparation and imaging}

The $(\mathrm{R}, \mathrm{R}) \mathrm{QNB}$ isomer was synthesised by the Department of Radiopharmacy, Glasgow University, and was subsequently labelled locally with ${ }^{123}$ I using a high performance liquid chromatographic technique. ${ }^{6}$ Five hours after the intravenous administration of $160 \mathrm{MBq}{ }^{123} \mathrm{I}-\mathrm{QNB}$, the subjects underwent a 30 minute tomographic acquisition on a SMV DST-XL dual head gamma camera. These projections were prefiltered, corrected for decay and attenuation, and reconstructed with a ramp filter. The statistical parametric software package (SPM99) was used for image analysis. ${ }^{7}$ The reconstructed images were registered to a single photon emission computed tomographic (SPECT) template image set in standardised stereotactic space, smoothed, and normalised to the mean count within the image. ${ }^{8}$

\section{Image analyses}

The following analyses of the SPM maps of the ${ }^{123} \mathrm{I}-\mathrm{QNB}$ images were undertaken:

- Assessment of associations between the ${ }^{123}$ I-QNB images and the psychometric assessment scores using linear regression analysis;

- Group comparison ( $t$ test) of the baseline patient images $v$ the controls;

- Group comparison ( $t$ test) of the baseline images of the actively treated patient group $v$ the placebo group; 
- Paired $t$ test of the baseline and four month follow up patient images for those on active treatment;

- Paired $t$ test of the baseline and four month follow up patient images for those on placebo;

- Group comparison ( $t$ test) of the differences between the baseline and four month follow up images for the actively treated group $v$ the placebo group.

Each comparison within SPM99 produced a three dimensional statistical map of voxels showing significantly reduced counts that was displayed in three orthogonal projections. Voxels were included in the map if their uncorrected $p$ value was less than 0.001 . The overall statistical significance, referred to as the set level within SPM99, was assessed using a threshold $\mathrm{p}$ value of 0.05 , either over the whole cortex or over a predefined cortical region. ${ }^{9}$

The project received approval from the local research ethics committee and the Administration of Radioactive Substances advisory committee; patient consent was obtained in accordance with the declaration of Helsinki.

\section{RESULTS}

The median ages of the patient and control groups were 75 years (range 58 to 87 ) and 70 years (range 65 to 79 ), respectively; there was no significant difference between medians (Mann-Whitney test, $\mathrm{p}=0.20$ ). The ADAS-COG scores of two of the patients in this pilot study were excluded, one because of visual impairment and one because of withdrawal from the trial. The median ADAS-COG scores at baseline of the actively treated and placebo group were 23 (rangell to 34 ) and 15 (range 9 to 28 ), respectively; there was no significant difference between medians (MannWhitney test, $\mathrm{p}=0.27$ )

All 12 patients successfully underwent the baseline brain imaging and were randomised to receive either a cholinesterase inhibitor or placebo. Unfortunately one patient appeared intolerant of the allocated treatment. For this patient the code was broken and the treatment was found to be the active drug; the patient was therefore removed from the trial. The 11 remaining patients successfully completed the four months of active treatment or placebo, followed by repeat neuroimaging.

The six controls underwent neuroimaging on one occasion only. Jack-knifing the QNB control studies (a procedure whereby each of the six subjects is removed in turn and compared with the remaining five subjects) within SPM99 showed that one of these control subjects had significant abnormalities. A subsequent rCBF SPECT cerebral perfusion study demonstrated significant parieto-temporal hypoperfusion suggestive of early Alzheimer's disease. Consequently this control was withdrawn from the study and will be kept under medical review.

A significant association was noted between the initial ADAS-COG and the baseline ${ }^{123} \mathrm{I}-\mathrm{QNB}$ images such that greater impairment on psychometric testing was associated with reduced uptake of ${ }^{123} \mathrm{I}-\mathrm{QNB}(\mathrm{p}<0.05)$. This finding was based on the 10 patients who completed brain imaging and had complete ADAS-COG assessment.

No significant group differences (placebo $v$ controls) were noted on the changes in neuropsychometry, nor were any significant associations found between the sequential changes on psychometric assessment and brain imaging in this pilot study.

SPM99 analysis did not show any significant group differences between the baseline scans of the 12 patients and the five subjects in the control group.

A group comparison of the baseline ${ }^{123} \mathrm{I}$-QNB studies of the six patients on active treatment with the five patients randomised to placebo did not show any significant differences.

The abnormalities demonstrated on imaging for an individual patient showed very similar patterns between baseline and follow up studies for each patient, indicating that the ${ }^{123} \mathrm{I}$-QNB imaging technique is highly reproducible; however, there was considerable variability in the patterns of abnormalities between patients.

A paired $t$ tests of the patients on active drug showed a reduction in tracer uptake in their four month follow up scan as compared with their baseline scan (311 voxels showed a significant decrease, $\mathrm{p}=0.028$; fig 1 ). Similarly, in the placebo group there was a reduction in the corresponding scans (745 voxels showed a decrease, $p=0.016$; fig 2 ). For both these comparisons, up to 300 voxels would have been expected by chance.

A group comparison within SPM99 of the differences of the paired scans in the actively treated group (follow up study minus baseline) with the differences of the paired scans in the placebo group showed greater differences in the placebo group. These changes were centred on the left parietotemporal region. By restricting the analysis to the posterior cortices (mild to moderate Alzheimer's disease predominantly affects parieto-temporal grey matter), a significant cluster could be identified in the region of the precuneus in the left medial parietal lobe $(\mathrm{p}=0.02)$.

\section{DISCUSSION}

In vivo imaging of the cerebral postsynaptic muscarinic receptor has been successfully undertaken using ${ }^{123} \mathrm{I}-\mathrm{QNB},{ }^{4}{ }^{10}$ which appears to target the Ml muscarinic receptor preferentially ${ }^{11}$; these receptors are predominantly located postsynaptically. Excellent correlations have been shown in healthy controls between the distributions of ${ }^{123} \mathrm{I}-\mathrm{QNB}$ uptake on in vivo imaging and muscarinic receptor densities in vitro. ${ }^{4}$

Reduced Ml receptor uptake in patients with Alzheimer's disease has been observed by others, ${ }^{4}{ }^{10}$ predominantly in the parieto-temporal cortices. Although this is at variance with several histopathological findings of normal receptor density, ${ }^{12-15}$ the most likely explanation is that, although the
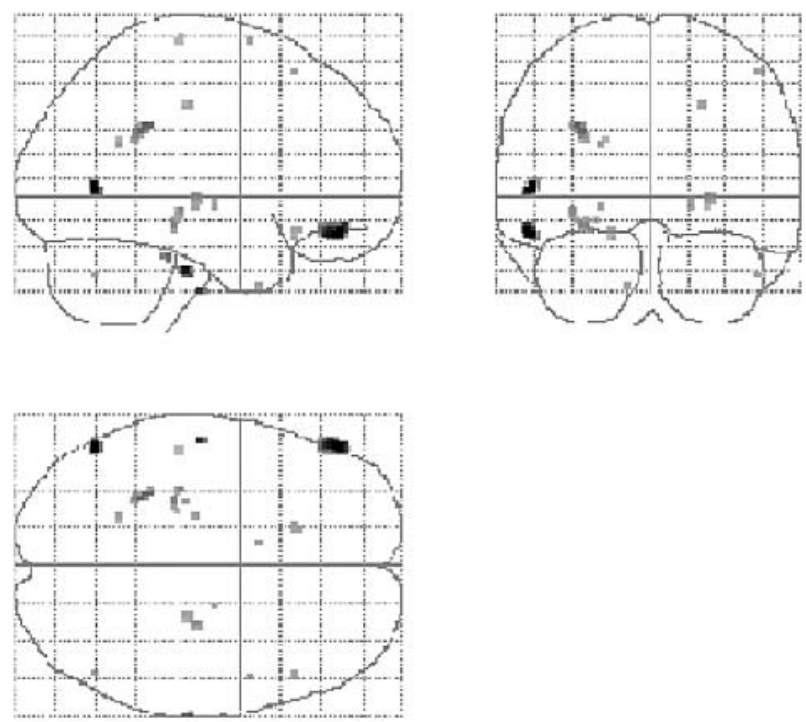

Figure 1 Areas of significant reduction of ${ }^{123}$ I-QNB uptake in the second scan as compared with the first for the patient group receiving active treatment $(p<0.001)$. (Results of SPM99 analysis depicted in the "glass brain" format-top left: composite sagittal view; top right: composite coronal view; bottom: composite transverse view.) 

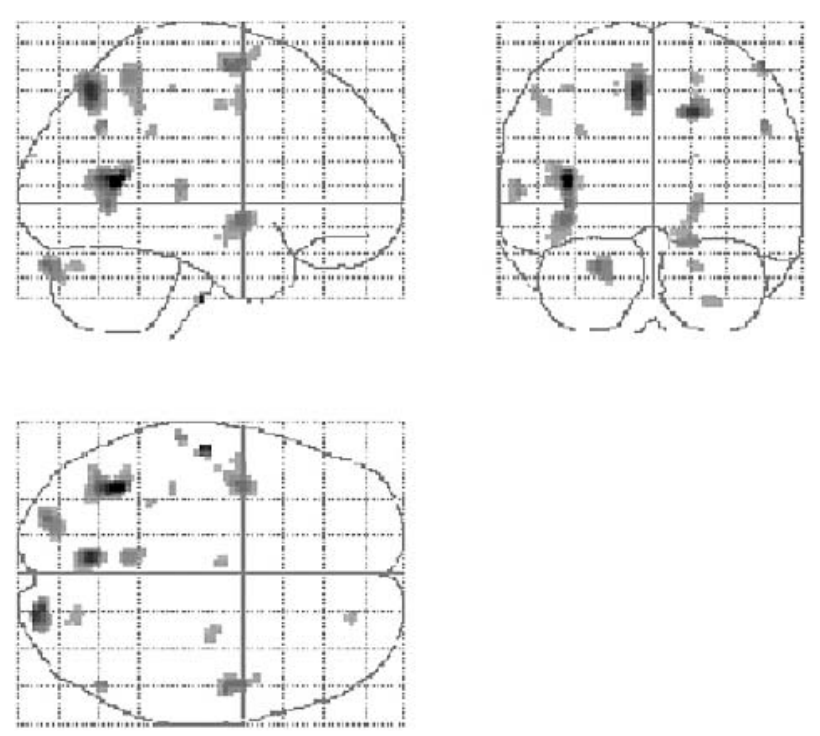

Figure 2 Areas of significant deterioration in the second scan as compared with the first for the patient group receiving placebo. Note the greater deterioration compared with figl. (Results of SPM99 analysis depicted in the "glass brain" format-top left: composite sagittal view; top right: composite coronal view; bottom: composite transverse view.)

receptors may be structurally present at necropsy, they are non-functioning. A possible mechanism is uncoupling between the Ml receptor and the G protein related signal cascade complex. ${ }^{16}$

In this pilot study we showed a significant relation between impaired ADAS-COG scores and deficits on ${ }^{123} \mathrm{I}-$ QNB images at baseline. This finding, and the lack of association between changes on psychometric scores and imaging, needs to be interpreted with caution given the small numbers.

Our inability to show significant group differences between the baseline images of the patients and the controls is most likely to be a reflection of several factors including the small number of subjects, the relatively mild disease severity, andmost probably the major factor-the wide interindividual variability of abnormal patient patterns in mild disease states.

In contrast to the considerable interindividual variability between the patterns of abnormalities on the patient scans, all patients showed similar patterns of abnormalities on their individual pair of scans (baseline and follow up), indicating creditable intraindividual reproducibility. Repeat imaging of the controls was not considered appropriate on radiation grounds. However, we believe that the changes in a patient in a four month period would be minimal. This excellent intraindividual reproducibility should enable sequential studies of high power with a relatively modest number of subjects.

Group comparisons of the paired scans using SPM99 showed a significantly greater reduction in the QNB uptake in patients taking placebo than in those on active treatment. Interestingly, the localisation of a predominant cluster in the left precuneus is consistent with recent findings of early involvement of this medial-parietal region in mild Alzheimer's disease..$^{17} 18$

It is unlikely that the potentially increased levels of endogenous acetylcholine in the actively treated group would affect the ligand binding. (RR)-QNB has a higher affinity at Ml muscarinic receptors than agonists such as acetylcholine. ${ }^{11} 1920$ An in vivo animal study using the positron emission tomography (PET) ligand ${ }^{18} \mathrm{~F}$-FP-TZTP to target the M1 and M2 muscarinic receptors showed only a nonsignificant reduction in cortical ligand binding when acetylcholine concentrations were increased by the administration of the acetylcholinesterase inhibitor physostigmine. ${ }^{21}$ In our study, any displacement of the QNB ligand by raised endogenous levels of acetylcholine in the actively treated group would have underestimated the significant differences noted in receptor binding between the actively treated and placebo groups.

\section{Conclusions}

The results of this pilot study show that patients on cholinergic treatment have better preservation of $\mathrm{Ml}$ receptor binding to ${ }^{123} \mathrm{I}-\mathrm{QNB}$ than those receiving placebo. This suggests a possible neuroprotective role for cholinergic treatment in Alzheimer's disease.

\section{ACKNOWLEDGEMENTS}

We would like to express our gratitude to the Welcome Clinical Research Facility, Southampton, for the support throughout this project, to Dr M A Piggott, MRC/University Joint Centre Development for Clinical Brain Ageing, Newcastle Upon Tyne, for the advice on aspects of neuropharmacology, to Mrs L Bolton for her administrative and secretarial contribution, and to Messrs J Williams and J Langford for their imaging assistance. The study was funded by grants from PPP Healthcare Medical Trust (AMRC), and HOPE (Wessex Medical Trust), Southampton. PMK was awarded a Research and Development Fellowship from Southampton University Hospitals Trust.

\section{Authors' affiliations \\ P M Kemp, M Zivanovic, J Thom, Department of Nuclear Medicine, Southampton University Hospitals Trust, Southampton, UK \\ C Holmes, S Wilkinson, D G Wilkinson, Memory Assessment and Research Centre, Moorgreen Hospital, Southampton \\ S Hoffmann, L Bolt, J Fleming, Department of Medical Physics and Bioengineering, Southampton University Hospitals Trust}

Competing interests: Pfizer-Eisai have awarded a project grant to DW and $\mathrm{CH}$, involved them in multicentre trials, and contributed to their expenses for conference presentations.

Correspondence to: Dr Paul M Kemp, Department of Nuclear Medicine, Southampton University Hospitals Trust, Southampton SO16, 6YD, UK; paul.kemp@suht.swest.nhs.uk

Received 23 December 2002

In revised form 7 May 2003

Accepted 16 May 2003

\section{REFERENCES}

1 Coyle JT, Price DL, Delong MR. Alzheimer's disease: a disorder of cortical cholinergic innervation. Science 1983;219:1184-90.

2 O'Brien JT, Ballard CG Drugs for Alzheimer's disease. Cholinesterase inhibitors passed NICE's hurdle. BMJ 2001:323:123-4.

3 Coyle C, Kershaw P. Galantamine. A cholinesterase inhibitor that allosterically modulates nicotinic receptors: effects on the course of Alzheimer's disease. Biol Psychiatry 2001;49:289-99.

4 Weinberger DR, Gibson R, Coppola R, et al. The distribution of cerebral muscarinic acetylcholine receptors in vivo in patients with dementia. Arch Neurol 1991;48:169-76.

5 McKhann G, Drachman D, Folstein M, et al. Clinical diagnosis of Alzheimer's disease: report of the NINCDS-ADRDA Work Group under the auspices of the Department of Health and Human Services Task Force on Alzheimer's Disease. Neurology 1984;34:939-44.

6 Owens J, Murray T, McCulloch J, et al. Synthesis of (R,R) I123-QNB, a SPECT imaging agent for cerebral muscarinic acetylcholine receptors in vivo. J Labelled Compounds Radiopharmaceuticals 1992;31:45-60.

7 Friston KJ, Holmes AP, Worsley KJ, et al. Statistical Parametric Maps in Functional Imaging: A General Linear Approach. Hum Brain Map 1995:2:189-210.

8 Tailairach J, Tournoux P. Co-planar stereotactic atlas of the human brain. Stuttgart: Thieme, 1988.

9 Colloby SJ, Fenwick JD, Williams ED, et al. A comparison of $99 \mathrm{mTc}-\mathrm{HMPAO}$ SPET changes in dementia with Lewy Bodies and Alzheimer's disease using statistical parametric mapping. Eur J Nucl Med 2002;29:615-22. 
10 Wyper DJ, Brown D, Patterson J, et al. Deficits in iodine-labelled 3quinuclidinyl benzilate binding in relation to cerebral blood flow in patients with Alzheimer's disease. Eur J Nucl Med 1993;20:379-86.

11 Piggott M, Owens J, O'Brien J, et al. Comparative distribution of binding of the muscarinic receptor ligands pirenzepine, AF-DX 384, and $(R, R)-I-Q N B$ and $(R, S)-I-Q N B$ to human brain. $J$ Chem Neuroanat 2002;24:211-13.

12 Caulfield MP, Straghan DW, Cross AJ, et al. Cortical muscarinic subtypes and Alzheimer's disease Lancet 1982:ii:1277.

13 Mash DC, Flynn DD, Potter LT. Loss of M2 muscarinic receptors in the cerebral cortex in Alzheimer's disease and experimental cholinergic denervation. Science 1985;228: $1115-17$.

14 Shiozaki K, Iseki E, Uchiyama $\mathrm{H}$, et al. Alterations of muscarinic acetylcholine receptor subtypes in diffuse Lewy body disease: relationship to Alzheimer's disease. J Neurol Neurosurg Psychiatry 1989;67:209-13.

15 Dewar D. Neurotransmitter abnormalities associated with the neuropathology of Alzheimer's disease. In: Kerwin R, ed. Cambridge medical reviews: neurology and psychiatry, vol 1. Cambridge: Cambridge University Press, 1991:61-94.
16 Flynn DD, Weinstein DA, Mash DC. Loss of high-affinity agonist binding to $\mathrm{m} 1$ muscarinic receptors in Alzheimer's Disease: implications for the failure of cholinergic replacement therapies. Ann Neurol 1991;29:256-62.

17 Matsuda H. Cerebral blood flow and metabolic abnormalities in Alzheimer's disease (review). Ann Nucl Med 2001 :15:85-92.

18 Bradley KM, O'Sullivan VT, Soper NDW, et al. Cerebral perfusion SPECT correlated with Braak pathological stage in Alzheimer's disease. Brain 2002;125:1772-81.

19 Paterson DS. Imaging cholinergic function in-vivo in the brain with radioiodinated stereoisomers of quinucidinyl benzilate. Glasgow: University of Glasgow, 1998; [Thesis]

20 Quirion R, Araujo D, Regenold W, et al. Characterization and quantitative autoradiographic distribution of ${ }^{3} \mathrm{H}$-acetylcholine muscarinic receptors in mammalian brain. Apparent labelling of an M2-like receptor sub-type. Neuroscience 1989;29:271-89.

21 Kieswetter DO, Carson RE, Jagoda EM, et al. Using single photon emission tomography (SPECT) and positron emission tomography (PET) to trace the distribution of muscarinic acetylcholine receptor binding radioligands. Life Sci 1999;64:511-18.

\section{HISTORICAL NOTE}

\section{Cerebral embolism in endocarditis: William Senhouse Kirkes (1823-64)}

T he distinction between thrombosis and haemorrhage was unclear until the mid-19th century, ${ }^{1}$ despite the clinical and pathological descriptions of Abercrombie, Cheyne, Cooke, and, in France, Serres. Small softenings were first designated lacunes by Dechambres in 1838. Van Swieten, ${ }^{2}$ far ahead of his time, postulated embolism arising in the heart and great vessels. ${ }^{3}$

After Virchow, ${ }^{45}$ William Senhouse Kirkes (1823-64) published one of the earliest descriptions of cerebral embolism associated with infective endocarditis, which together with the later paper of Samuel Wilks brought this disease to the attention of doctors. Kirkes' paper $^{6}$ described three patients.

"Margaret Shaw at 34 was admitted to St Bartholomew's hospital under Dr Roupell...on account of pains in her lower limbs and general debility. A loud systolic murmur was heard all over the cardiac region.... While sitting up in bed eating her dinner, she suddenly fell back as if fainting... and when attended to was found speechless, though not unconscious, and partially hemiplegic on the left side[sic]. The hemiplegia increased... and gradually became complete...but without loss of consciousness for five days, when she quietly died."

"On examining the body...the right corpus striatum was softened to an extreme degree...the corresponding optic thalamus was healthy; but a condition of pale softening, similar to that affecting the corpus striatum, existed also in considerable extent in the posterior lobe of the right cerebral hemisphere...all other parts of the brain were healthy. The right middle cerebral artery just at its commencement was plugged up by a small nodule of firm, whitish, fibrinouslooking substance... The right cavities and left auricle [of the heart] contained recent separated coagula; the fibrine firm and whitish. The mitral valve was much diseased, the auricular surface of its large cusp being beset with large warty excrescences of adherent blood-stained fibrine..."

Although, the report did not indicate whether the speechless patient was left handed, it gives convincing details of embolic infarcts in the spleen, right kidney, and right iliac artery.
His second patient was a woman of 24 , with mitral valve "fungous condylomatous growths", who had a right hemiplegia with striatal and left cerebral infarction and middle cerebral artery occlusion. The third was a man aged 24 , with left hemiplegia, who died after a fluctuating illness over two months. He had vegetations on the aortic, tricuspid, and mitral valves and right middle cerebral artery occlusion; he also had fibrin clots in the left lateral sinus and left jugular and iliac veins.

Kirkes was physician to St Bartholomew's Hospital, amiable, and much respected. His Handbook of physiology was popular and was deservedly held as an authority. Together with Virchow, the name of Kirkes stands firmly connected with the subject of embolism, one of the most fruitful inquiries in modern pathology. While attending a meeting (nominated by the Admiralty and Horse Guards) to inquire into venereal disease, he fell ill and met a premature death with pleurisy, pericarditis, and haematuria.

\section{Beverley Road, Anlaby, Hull HU10 7BG, UK} imspearce@freenet.co.uk

\section{Reference}

1 Lidell JA. A treatise on apoplexy, cerebral hemorrhage, cerebral embolism, cerebral rheumatism, and epidemic cerebro-spinal meningitis. New York Wm. Wood, 1873; vol 8;xix395.

2 van Swieten G. Of the apoplexy, palsy and epilepsy. Commentaries on the aphorisms of Dr. Herman Boerhaave. London: John \& Paul Knapton. Translation from 6 volumes (Lugduni Batavorum, J \& H Verbeek) 1742-76). 1754 , Vol 10.

3 Pearce JMS. van Swieten's concept of cerebral embolic stroke. I Neurol Neurosurg Psychiatry 2002;73:153.

4 Virchow RLK. Concerning the acute inflammation of the arteries. Arch für path Anat u Physiol und fur klink Med. Berlin 1847;1:272-4.

5 Pearce JMS. Rudolf Ludwig Karl Virchow (1821-1902). J Neurol 2002;249:492-3

6 Kirkes WS. Detachment of fibrinous deposits from the interior of the heart, and their mixture with the circulating blood. Med Chir TransLondon 1852;35:281-324. Cited in: Major RH. Classic descriptions of disease. Springfield: Thomas, 3rd edn 6th printing, 1965:462-4. 